\title{
Object-spatial Approach to Studying Fine Art: Development of Three-dimensional and Spatial Perception among Students
}

\author{
Lubov Savenkova ${ }^{1} \&$ Natalia Fomina ${ }^{2}$ \\ 1,2 Doctor of Education, Professor, Corresponding Member of the Russian Academy of \\ Education, Institute of Artistic Education and Cultural Studies of the Russian Academy of \\ Education. Corresponding email: lgbloknot@mail.ru
}

Received May o9, 2017; Revised July 28, 2017; Accepted July 30, 2017; Published August 17, 2017.

\begin{abstract}
The article reveals an object-spatial approach to the process of fine arts studying by children of different ages. The authors justify the pedagogical directions of children's education, which have been developed and scientifically substantiated in the works of the outstanding psychologist, educator and art historian A.V. Bakushinsky (1883-1939). The authors distinguish the basic directions of the mastery of object-spatial types of activities by students of different ages. It is shown how the ideas of child's art education, generated in the beginning of the zoth century, are refracted in modern children's education.
\end{abstract}

Keywords: art education, pedagogics of art, space and environment, spatial perception, interaction of arts, integrated training, child's worldview

\section{Introduction}

The theory of the subject-spatial mastery of fine arts is considered by the condition for the holistic art education of students, if it is based on a category of an artistic image. Such integrated education is based on the provision of rethinking of a fundamental problem of modern training of schoolchildren for real life from the standpoint of artistic pedagogy. The study is aimed at the revival and development of the best ideas that enriched artistic pedagogy of the past, making up its methodological essence. The theoretical platform of domestic artistic pedagogy is oriented to an "activity approach", an active role of the child's actual independent practical artistic activity, which requires an adequate organization of pedagogic guidance and the object-spatial environment, within which children develop.

\section{A.V. Bakushinsky, researcher of children's artistic creativity}

The topicality of the problem is connected with the propensity of modern children to perceive reality through a flat screen (outside the real space), which may complicate their threedimensional perception of reality and its mastering. The study of the problem in the domestic psycho-pedagogical science dates back to the first decades of the 2oth century. The most

(C) AesthetixMS 2016. This Open Access article is published under a Creative Commons Attribution Non-Commercial 4.0 International License (http://creativecommons.org/licenses/by-nc/4.0/), which permits non-commercial re-use, distribution, and reproduction in any medium, provided the original work is properly cited. For citation use the DOI. For commercial re-use, please contact editor@rupkatha.com. 
complete reflection on this problem was presented in the theoretical works of the psychologist, art historian and pedagogue A.V. Bakushinsky (1883-1939).

A.V. Bakushinsky studied the artistic creativity of children "on the basis of spatial arts" in order to understand the history of the development of art. He studied the history of spatial arts of the East and West in order to understand the evolution of the world perception of a growing up person. Trying to guess what the art of the near future would be, he wrote: "The new worldview must be synthetic, preserving the personality and the whole sphere of its artistic expression as a precious heritage of the culture of the West and restoring its strong organic connection with the general, suprapersonal as the ultimate source of all norms, and, certainly, the artistic ones ... " (Bakushinsky, 1981; pp. 47).

The three-dimensional and spatial perception is reflected in the children's graphic activity in the specificity of the depiction of space and objects that fill it: their size, shape, location and organization of the composition of the sheet.

As a result of studying the aesthetic and artistic development of children from birth to adolescence, A.V. Bakushinsky identified the main phases of artistic development that condition the development of the three-dimensional and spatial perception as an indicator of the worldview formation. In comparison with his predecessors, A.V. Bakushinsky significantly expanded the studied area of artistic creativity of children from drawing to "children's art", including in this concept "children's architecture, sculpture, painting and drawing" (Bakushinsky 1925; pp. 9).

As a result of the analysis of the process of development of spatial-volumetric and temporal perceptions in "children's construction", "children's modeling and sculpture", in the "creativity on the plane" (drawing and painting) and ornamental decorative form, the scientist succeeded in identifying the phases of artistic development, which, in his opinion, each person inevitably passes in his/her development. They are the period of the motor-visual adjustment of the psyche, the period of the visual-motor adjustment of the psyche and the period of the visual adjustment of the psyche. The first period, as a rule, corresponds to preschool childhood, the second - to the youngest teenage age, and the third - to the senior and adolescent age.

\section{A.V. Bakushinsky's ideas of the aesthetic education system}

The main conclusion of A.V. Bakushinsky for the system of aesthetic education can be presented as follows: "... in its methods it must proceed from the unconditional recognition and establishment of autonomous values of age, not allowing the imposition of false and unsound values from outside. It should be a system that releases creative power, but not a system of accumulation and training of mechanically and analytically acquired knowledge and skills, organically unjustified and thus extremely undurable" (Bakushinsky 1925, pp. 156). As the most important task of aesthetic education, A.V. Bakushinsky considered the formation of a new worldview, which, in his opinion, should be "synthetic". Among the unsolved but future-oriented tasks of art pedagogy, A.V. Bakushinsky considered "the problem of integrated teaching and its connection with the tasks of artistic upbringing. The reasons are: novelty, extreme complexity and difficulty of the task. In the near future, investigations, observations and public discussion should be devoted to studying this task" (Bakushinsky 1925, pp. 3).

In the years 1970-2010, the followers of the scientific school of A.V. Bakushinsky - Yusov

B.P. (2004), Savenkova L.G. (2014), Fomina N.N. (2014) studied the problem of the development of the three-dimensional perception of students. The scientists have confirmed from different 
positions the theoretical significance of A.V. Bakushinsky's research for the pedagogy of art; his basic conclusions have been introduced into scientific usage from the standpoint of modern views and directions of work with children of different ages. In the research of the scientists, the methods of the development of the three-dimensional and spatial perception and object-spatial directions of work with pupils of different ages in conditions of general and additional art education have been described. The relevance of the conclusion about the necessity of forming a new "synthetic" world outlook in the process of "integrated teaching", in particular, "polyartistic" mastering of fine arts (Yusov 1975), has been demonstrated. The research methods of the scientist, which opened the possibility of obtaining reliable results, have a scientific value.

The conclusions of A.V. Bakushinsky's research are checked and corrected at the present stage by applying the diagnostic techniques developed by him for studying the development of the three-dimensional and spatial perception of children at each age stage. This allows considering the three-dimensional and spatial activity in teaching fine arts as a special pedagogical category aimed at solving the problems of shaping the artistic outlook of students.

Such a statement, in our opinion, is quite legitimate, since in aesthetics, SPACE is regarded as a category in the classification of art forms. In the further development of this approach, the semantic value of the internal form of the word "space" is used in the pedagogy of art. This includes the extent, the really perceived dimension, its imaginative representation through color, light, sounds, melody, sounding of the word, sensation of silence, form of the object, architectural space and natural landscape. Since an empty space, not filled with objects, color, sounds, smells, action, is difficult to imagine, it is identified in this case with the concept of environment. Hence, an object-spatial direction emerges when the whole process of fine arts teaching at school should be directed not so much to the formation of certain graphic and practical skills of the work in a particular type of activity (as it often happens in practice), as to the development of children's emotional-sensual sphere, the disclosure of their internal readiness for the active creative self-expression in art, self-development, self-improvement and moderate involvement in the process of improving the culture of their nation.

The appropriateness of the object-spatial mastering of any art is conditioned in the study by the following positions:

1) Every realistic image has in its basis an object-spatial form of understanding the reality, which reflects the worldview of the artist (V.A. Favorsky 1988, pp. 72);

2) At the preschool and school age, art should be mastered in an active creative action, in the manifold manifestations of the child in the creative work, in the perception of the surrounding space of life and him/herself in this space (Bakushinsky 1925; Vygotsky 1967);

3) The object-transforming activity with real space is the initial form of all activities of the child such as game, education and labor (V.V. Davydov 1996, pp. 102).

When working with children, the concept of "space" is viewed as an imaginary activity that can be considered as an opportunity TO TRAVEL around the world; and as art - the necessity to live out a spatial image of art (master, study and understand it from different points of view ) (Savenkova 2014, pp. 30). The foregoing is due to the fact that in the modern period, a real need has arisen for schools in Russia to teach children: to adequately perceive the visual world of information and to navigate the surrounding world of information; to understand and assimilate the visual world selectively and be able to adapt it to oneself; to form an artistic visual taste; to develop the ability to quickly change the types of activities, the ability for self-development and 
self-improvement. All this presupposes: the accumulation of a certain experience of the emotional-figurative perception of not only art but also the environment (natural, artistic and social); the development of the emotion and feeling sphere; learning to consider separate phenomena of life in unity with the whole environment; preparing for the improvement of the culture of the people according to one's capabilities.

Space is viewed from three positions: 1 ) as an organizing structure of a creative piece; 2 ) the life of a work of art in a certain space; 3 ) the dependence of the space of a work of art on the historical, natural and subject spaces where the artist lived and created that is the "environment: the landscape and ethnic ones" (L.N. Gumilev 1990) in the real life of the artist him/herself. From these positions, the levels of artistic integration, in connection with the specificities of the age of students, are described as follows: the first level is an ecological approach to the individual development of the perception and activity of the emerging personality (the preschool and primary school age); the second level is an integrated approach to the process of art education, the formation of integrity of thinking, a broad view of the world and art (middle school age); the third level is the individuality of artistic and imaginative thinking, the formation of systematic (philosophical, research) artistic thinking in the conditions of mastering the space (senior school age). (Figure 1).

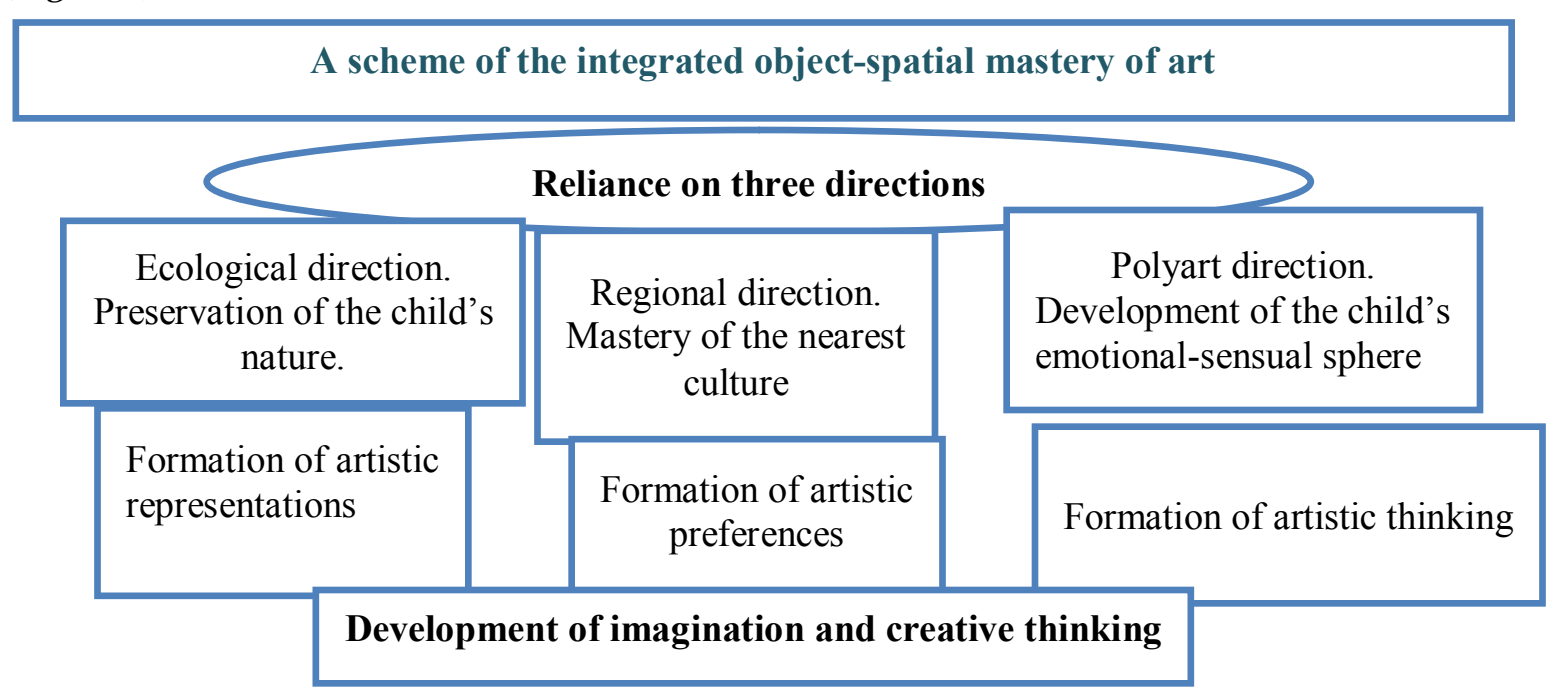

Figure 1. A scheme of the integrated object-spatial mastery of art

This approach involves the rethinking of the overall structure of organization of training; special preparation of students for the process of perception, understanding and comprehension of information (from the standpoint of science, the history of development of culture, the specific characteristics of various arts, the natural environment); formation of the concepts and ideas about the world as a single whole. The pedagogical meaning of integrated learning consists in planning a cycle of classes on mastering, for example, a single concept, an artistic image, an area of discussion, etc., which are important for several teachers working with the same collective of children, in the context of the interaction between basic and additional education.

\section{Methods of research}

The research methodology included the theoretical and pilot-experimental work: the analysis of Russian and foreign literature, the study of school practice and systematic collections of products 
of children's artistic activities in our country and abroad, the generalization of the pedagogical experience, specially organized experimental and pilot-methodological research.

As indicated above, the analysis of research on the development of students' object-spatial representations has an integrated character and also dates back to the psychological and pedagogical study of A.V. Bakushinsky. It includes a theoretical analysis of philosophical, psychological, art-historical, and pedagogical views on the problem; an analysis of the practice of art education in this field; diagnostics of the specific features of formation of the threedimensional and spatial perception by means of tests first applied by A.V. Bakushinsky and his followers (an image of a cube, a pond, a ring dance).

As effective methods, we can mention a pedagogical experiment, observation of children in the process of creative activity, analysis from the perspective of the studied problem of a series of drawings of one child during a certain period of development. An evidence of the reliability of the results of A.V. Bakushinsky's research is typical collections of children's drawings and educational works of the 1920s, which constitute "A.V. Bakushinsky's fund" in the international collection of children's drawings at the Institute of Art Education and Cultural Studies of the Russian Academy of Education. The drawings were created spontaneously or according to certain tests, as well as in schools in the classes according to the program "Fine Arts and Art Work", developed under the guidance of A.V. Bakushinsky.

\section{Results and discussion}

The artistic activity is defined in the study as a relatively independent component in the general structure of the types of activities of schoolchildren; its difference and relationship with the game and categorical knowledge are shown. In turn, the artistic activity includes components of other directions of schoolchildren upbringing and development and is a factor of their optimization. The object-spatial approach to the organization of the integrated mastery of fine arts at school makes it possible to achieve sufficient completeness and integrity in the pedagogical theory and in the practice of art education and upbringing, provided that the stages and levels of integration are observed in terms of logic, continuity and consistency of age levels. The integrity is the first stage of artistic integration - this is a look at other arts from the point of view of one art (in this case, fine art); the second stage is the relationship and interaction of fine arts with the surrounding life, nature, the history of culture; the third stage - artistic thinking - is an expression of life, nature, art through the system of artistic means. (Yusov B.P.; Eisner 1979)

A.V. Bakushinsky, a founder of the system of the "complex teaching method" in the school practice, argued that "a complex as a method of the pedagogical impact on a child should be constructed based on a CREATIVE IMAGE-EXPERIENCE, not on a topic-formula" (Art in Labor Schools, 1926; Shestakov and Yusov 1968; Revolution-Art-Children, 1966).

As a result, A.V. Bakushinsky arrived at a system in which the interaction of various arts (package) is involved in artistic development. The goal of artistic upbringing (which can be realized as a result of artistic development) is the "culture of the creative personality", capable of "becoming a creator in the field of the chosen profession".

A.V. Bakushinsky perceives the child holistically, in all manifestations of the development, expressed in the ways of interacting with space in motion, rhythm, various forms of creation. A selection of drawings of children from the preschool age to adolescence (In the collection of the Institute of Art Education and Cultural Studies) reflects a system of aesthetic education, in which 
the task of forming the three-dimensional perception includes the tasks on the development of observation and imagination, study of cultures of various peoples, arts and crafts, posters, book art and theater. The main experimental base was the Seventh Experimental Art Education Station of the People's Commissariat of Education of the RSFSR, which included a first-level school in the village of Uspenskoye (near Zvenigorod) and a second-level school named after Karl Marx in Moscow. In A.V. Bakushinsky's program, the following complex topics are specially highlighted: "Diagram of the city improvement and the city in the future", "Ornament on the things of everyday life", "Primitive buildings. Dwellings", "Village and city construction", drawings connected with "natural science", drawings according to compositional assignments (symmetry), images of "Eastern dwellings". This provided the opportunities for creativity of the teacher and pupil, as evidenced by the image structure of many drawings in which the students' awareness of contemporary art is visible. The influence of constructivism is noticeable (especially, in the book graphic arts). Students tend to give their drawings the appearance of a finished easel composition: seemingly purely educational tasks ("hatching", drawings of triangles and other geometric figures), they are all framed, thought over compositionally. The drawings reflect the life experiences and impressions of children. The study of different tasks shows the development of individual students, which one recognizes through the expressive features of the drawing.

The staff of the Tretyakov Gallery, the Pedagogical Theater, the Moscow Conservatory, and a wide circle of artists and art critics were involved in the pedagogical experiment. The introduction into art in the school was of a complex character, linking the development of children with different types of art and artistic creation. This is evidenced, in particular, by the album "Village Uspenskoe", which combines drawings and stories about the surrounding nature, about life, which in the most intimate way, in a country way, is tied with the change of seasons, with peasant labor. Teachers tried not to interfere with the flow of impressions of students when creating these small works, revealing the sorrows and joys of the authors. G.I. Sokolov, who taught the Russian language and literature in the 7 th experimental station, formulated the task of children's free creativity in the following words: "to open the eyes of children to the living environment as an inexhaustible source of exciting impressions and various creative opportunities" (Glinskaya 1973, pp. 294).

The drawings of the second-level pupils of the Karl Marx School are systematized in accordance with the following educational and creative problems, organic for the artistic development of senior adolescents: "Composition"; "Still life"; "Sketches of Man"; "Drawing from nature. Human figure. Aquarelle. Graphic Approach" 1926-27; "Landscape"; "Work on the head of a person (portrait)" (Nos. 251-267). The earliest drawings were dated by the year 1924, the latest by the year of 1930. The age of students, name and surname were sometimes not indicated in the drawings. The oldest students were 15-16 years old.

The teachers, engaged with the students of the second level, were trying to overcome the "fading" of artistic and creative activity of adolescents in the field of fine arts. V.E. Pestel, an artistteacher who taught at the Karl Marx school, defined her method in the article "Methodological Issues of Teaching Fine Arts in the Second-Level School", where she wrote: "Through a creative, conscious process, one is introduced into the understanding of art; through the knowledge of creative tension, to the knowledge of the surrounding world. This new path is a way of cognizing the world through art, through creative process" (Bakushinsky 1981, pp. 142).

Working with children, a well-known drawing artist N.N. Kupreyanov set for himself a pedagogical task of "the development of visual memory and the habit of analyzing the visible in the direction of extracting an image from it" (Bakushinsky 1925; pp. 201). 
The artistic development of adolescents was multifaceted. Drawing in the class was combined with home sketches of observations and nature outings, visits to art museums and artists' studios. Mastering of contemporary art ("OST", "Bubnovy Valet" and other directions) was achieved by students in the process of working on their own design, in the search for a figurative solution of composition, the color system.

A selection of drawings of students in the 1920s, created using A.V. Bakushinsky's system, gives grounds to believe that he and his colleagues discovered a way to overcome the "fading" of the creative talents of adolescents. The way was through the progressive overcoming of the difficulties of understanding and depicting space within the framework of the features of contemporary art, oriented toward the constructive embodiment of artistic designs in different types of art: in architecture, sculpture, painting and design.

As continuation of the research related to the object-spatial mastery of fine arts several decades after A.V. Bakushinsky (1920-40-ies) and his follower G.P. Glinskaya (1960-70-ies in Russia) (Glinskaya 1973), including foreign researchers of the 2oth century (G. Kershensteiner, 1914), a group of American researchers (SEMREL - Barkan M. (Barkan, Chapman and Kern 1970), with modern children, current relevance and timeliness of this direction should be emphasized. It has been proved that the object-spatial approach facilitates the understanding of the process of independent artistic creativity by a child (later by adolescents and senior students), allows them to feel at the center of this process. The studies conducted in the Institute of Art Education and Cultural Studies in the early 1980-ies up to the present time allowed constructing the dynamics of the inclusion of this direction in the work with students in grades 1 to 9 .

The practical significance of the research is primarily related to the fact that the directions of reflections and activities are revealed through the interrelation: nature - man - environment art. The principles of the unity of Nature, Culture and Man are also constructed on this fact. as follows:

The age dynamics of developing areas of the work in terms of the object-spatial activity are

$1^{\text {st }}$ grade. Reliance on the child's nature - switching his/her attention from one activity to another and this is related, first of all, to the development of children's observation skills. Study of the surrounding world, open and closed space and acting in it. Formation of the ability to express the observed in an artistic product.

Such reflections on the child's natural development, his/her innate ability to perceive and act in different types of artistic creativity and the importance of the complex interaction of arts in the all-round creative upbringing of children are reflected in the works of K.D. Ushinsky (1945), L.S. Vygotsky (Vygotsky 1967), J. Dewey (1916), E.A. Flerina (1921).

$2^{\text {nd }}$ grade. Development of the surrounding natural and object-spatial environment. Formation of the idea of the close interrelation of objects of the environment. The development of the child's mental processes and his/her inclusion into the world of fairy-tale transformations in own drawings are the most important part of this.

The importance of such mental processes as emotions, intuition, imagination, attention, imaginative thinking and other processes in the child's development is confirmed by the studies conducted by R. Arnheim (1994) and L.S. Vygotsky (1967);

3rd grade. Formation of ideas about human being in the surrounding nature and the object-spatial environment. Development of the concept of the dependence of architecture, 
customs, clothing, art on climate and landscape. The first ideas about the artist's work and his/her artistic images.

4th grade. Formation of ideas about the features of human development of the surrounding landscape. Development of logical thinking. Establishment of the relationship of folk art with traditions and the unique features of the surrounding nature. Open and closed space, its representation.

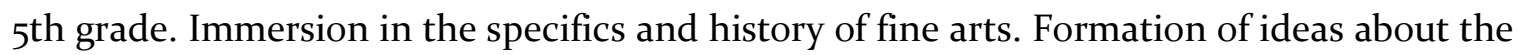
relationship: material - form - color - the practical importance of the object. Understanding the concepts: the surrounding object environment of a person as a reflection of his/her worldview, interests and preferences.

Introduction of integrated training in practice and the role of integration processes in the development of society (B.M. Kedrov (1973), B.P. Yusov (2004a).

6th grade. Formation of concepts about the processes of man's mastering (inhabiting) of the natural landscape in different historical periods. History of the development of architecture as a reflection of the worldview of man.

Development of ideas about the artistic form in art.

K. Levi-Strauss (2014) and E.B. Taylor (1989) wrote about the problem of the evolution of primitive culture and its dependence on climatic and natural conditions of existence; the formation of the scientific-theoretical school and the strategy of its development.

7 th grade. Spatial location of objects in the physical and natural environment. Functional significance of each link in the natural structure. Fine arts and science. The motives of nature in static forms of art (bioarchitecture, stylization). Drawing natural objects from nature, images and sketches of the human body. The role of fine arts in theater, cinema, cartoon.

P.A. Florensky pointed out a developing factor of the surrounding object-spatial environment and object-spatial activities in the development of artistic-creative thinking of children and their active manifestation in creativity (Florensky 1980).

8-9th grades. Form and content in art. Composition - construction - structure on a plane, in volume, in space. An idea of style in art. Mastering of artistic expressive means: composition, form, color, space, statics, dynamics, balance, symmetry, etc. Specifics of the perception of art (painting, graphics, sculpture, architecture, design, applied and decorative art). Improvisations in different types of art.

The works of well-known Russian researchers (A.V. Bakushinsky, L.S. Vygotsky, I.P. Glinskaya, G.I. Lerner (1977), N.A. Sakulina, E.E. Flerina, B.P. Yusov), as well as the analysis of foreign researchers, in particular J. Dewey, G. Kershensteiner, J. Piaget (1969), E.W. Eisner, M. Barkan and other scientists, have been used during the research. Seven developmental activities can be distinguished: visual-external observation and development of differentiated vision; transfer of the observed phenomenon (object, action, etc.) into an artistic form (drawing, construction, music, literary creation); own creativity of students, independent generation of creative product, social aspect of the studied material; the natural environment, the object environment, the musical environment, the architectural, theatrical ones, etc.; child and art (the ability to make up, create one's own artistic image through own "I"); a variety of forms of activities and materials. 
The stages and levels of the complex integrated direction in the mastery of fine arts presuppose the solution of the problem in terms of the following factors:

- Interaction of arts as the structural training organization.

- Harmony of the combination of the laws of the formation of architecture with the environment, creation of the emotional-artistic climate of space in the history of peoples - in terms of cultural studies.

- Spatial perception of the world by means of different arts - in terms of the psychological and pedagogical orientation.

- $\quad$ "Active living space" and acting in it - from the system-hierarchical point of view.

- The environment as a factor of space changes - in terms of art history in the light of social changes.

- Creation of the surrounding art space, sensitivity to the constructive art tasks, creation of art in action.

The theoretical analysis of modern scientific-pedagogical research on the attraction of schoolchildren to the object-spatial activity and their aesthetic education in the real world has shown that, unfortunately, no special studies have been carried out to determine the pedagogical conditions of this direction in the sphere of children's art education.

The types and forms of work in the studied area were linked in the research of educatorsscientists mainly with the applied nature of the work and with an emphasis on the decorative activity. Besides, a group of Russian artists-architects, who worked actively with children in the 1980-90-ies in art schools, the activities of which were mainly based on the implementation of architectural-spatial projects, the solution of design tasks, should be noted (I. Abayeva, V. Ermolaev, A.M. Kakushkin, A. Kirpichev). Such disconnection of artistic and aesthetic subjects from the real life makes it necessary to revise the curricula in terms of their significance in the formation of students' skills and ideas of the adaption of the acquired knowledge in specific practical activities. This actual call of the times to educate creatively active personalities dictates the need to improve pedagogical humanitarian technologies of the organization and conduct of art classes and create a special object-spatial learning environment.

\section{Conclusion}

The proposed age-related dynamics of the artistic development of schoolchildren during the years of study at school in the context of the mastery of certain types of artistic activity allows the gradual inclusion of a pupil in the process of the object-spatial study of fine arts. Practical significance of the research is to reveal the theoretical and practical basis of the system of fine arts teaching at school from the standpoint of the most important direction - the study of fine arts in terms of the object-spatial approach. This dynamics of artistic development can be used to specify the general theory of the integral personal development and the education of schoolchildren. The research results allow organizing the systematic artistic work with students in art classes in general-education schools, taking into account the specific correlation of different types of the visual activity and their interaction in the process of artistic development of schoolchildren of different ages, which can be used in the compilation of curricula, manuals and in teachers' advanced training. 
The ideas developed at the beginning of the 2oth century by outstanding scientists and researchers, such as A.V. Bakushinsky, and the methodology of research of artistic development, based on the study of true results of children's artistic-creative activity, retains their significance in modern pedagogy. It should be emphasized that the object-spatial approach allows developing children's SPACE OF IMAGINATION - the breadth and depth of imagination - by mastering the space of the history of culture, folk traditions and the space of different types of the artisticcreative activity. Thus, a problem of children's artistic and spiritual development will be solved on a completely different level.

\section{Acknowledgement}

The results stated in the article were obtained as part of the performance of State Task of the Ministry of Education and Science of the Russian Federation No. 27.7384.2017/8.9. We are grateful to the researchers of the Institute of Artistic Education and Cultural Studies of the Russian Academy of Education, which have been working for many years on studying A.V. Bakushinsky's heritage and developing his ideas in modern innovative approaches to the process of familiarizing children and young people with artistic and creative activity: L.V. Vysotskaya, N.V. Grosul, Yu.V. Golobokov, E.A. Ermolinskaya, T.A. Koptseva, I.N. Klyueva, E.P. Olesina, O.I. Pekina, Yu.N. Protopopov, O.I. Radomskaya, and O.A. Cheskidova.

\section{References}

1. Eisner E.W. (1979). The Educational Imagination: On the Design and Evaluation of School Programs. New York: Macmillan Co., Inc, pp. 293.

2. Arnheim R. (1994). New Essays on the Psychology of Art. Moscow: Prometheus, pp. 352.

3. Bakushinsky, A.V. (1925). Artistic Creation and Education. The Experience of Research on the Material of Spatial Arts. Moscow: New Moscow, pp. 220.

4. Barkan M., Chapman, L. H. and Kern, E. J. (1970). Guidelines: Curriculum Development for Aesthetic Education. Aesthetic Education Curriculum Program. Saint Louis: CEMPEL, INC., pp. 617.

5. Vygotsky, L.S. (1967). Imagination and Creativity in Childhood: Psychological Sketch. Second edition. Moscow: Prosveshcheniye, pp. 93.

6. Glinskaya, I.P. (1973). Pre-perspective Ways of Transferring Spatial Information and Some Issues of Teaching the Drawing of Younger Schoolchildren. In: Art Education at School: Set of Scientific Works. Leningrad, pp. 103-132.

7. Gumilev, L.N. (1990). The Geography of Ethnos in the Historical Period. Leningrad: Nauka Publ..

8. Davydov, V.V. (1996). The Theory of Developmental Teaching. Moscow: Intor, pp. 390.

9. Dewey J. (1916). Democracy and Education: An Introduction to the Philosophy of Education. New York: Macmillan

10. Art in Labor Schools. (1926). Moscow.

11. Shestakov, V.P. and Yusov, B.P. (1968). Art and Children: Aesthetic Education Abroad. Moscow: Art, pp. 273

12. Kedrov, B.M. (1973). On the Synthesis of Sciences. Issues of Philosophy, 3, 81. 
13. Kershensteiner, G. (1914). Development of Child's Artistic Creativity. Moscow: Sytina Publ., pp. 242.

14. Levi-Strauss, K. (1994). Primitive Thinking. Moscow: Respublika, pp. 384

15. Lerner, G.I. (1977). Perception of Spatial Bodies Presented in the Drawing. In: Managed Formation of Mental Processes. Moscow, pp. 7-22

16. Bakushinsky A.V. (1981). Linear Perspective in Art and Visual Perception of Real Space. Quoted after. Studies and Articles. Moscow: Soviet Artist

17. Piaget, J. (1969). Selected Psychological Works: Psychology of Intelligence. The Genesis of Number in a Child. Logic and Psychology. Moscow: Prosveshcheniye, pp. 659.

18. Revolution-Art-Children, Part 2. (1966). Moscow: Prosveshcheniye, pp. 230

19. Savenkova, L.G. (2014). Education of Man in the Space of World and Culture: Integration in the Pedagogy of Art. Moscow: MAGMU-RANKHIGS, pp. 160.

20. Taylor, E.B. (1989). Primitive Culture. Moscow: Political Literature, pp. 570.

21. Ushinsky, K.D. (1945). Selected Pedagogical Works. Moscow: Uchpedgiz

22. Favorsky, V.A. (1988). Literary and Theoretical Heritage. Moscow: Soviet Artist, pp. 380.

23. Flerina, E.A. (1921). The Role of the Material Environment in the Development of the Artistic and Creative Activity of a Preschooler. Moscow.

24. Florensky, P.A. (1980). The Analysis of Spatiality in Art Works. Decorative and Applied Art, 7, 24-29.

25. Fomina, N.N. (2014). Children's Artistic Creativity in the Space of Artistic Culture. Moscow: ALLRUSSIAN CENTER FOR ARTISTIC CREATIVITY, pp. 140.

26. Yusov, B.P. (2004). When all Arts are Together. Murmansk, pp. 120.

27. Yusov, B.P. (2004a). Interrelation of Cultural-Genetic Factors in Art-Pedagogical Education. Moscow: Sputnik, pp. 240.

28. Yusov, B.P. (1975). The Systematic Art Education and the Problem of Children's Leisure Time. In: Presentation des Exposes: Annexe (rapports ties exposes Anglais). INSEA 22-nd World Congress. General Conference; 7-th - 12-th July, 1975. Sevres: France, Centre International d'Etudes Pedagogiques. 